\title{
Ocular injuries caused by a stud gun
}

\author{
K. H. LIM \\ Outram Road General Hospital, Singapore
}

Accidental injuries have been caused by nails and studs fired from cartridge-operated fixing tools (nail or stud guns) designed to penetrate masonry or wood in the building industry. The muzzle velocity of such tools ( $1,400 \mathrm{ft}$. $(430 \mathrm{~m}$.)/sec.) is higher than that of a 0.22 in. $(6 \mathrm{~mm}$.) rifle $(\mathrm{I}, \mathrm{I} 45 \mathrm{ft}$. (350 m.)/sec.). Injuries and fatalities have been reported from Germany, America, the Soviet Union, Great Britain (Brit. med. J., I968), and Singapore (Lim, I964), but ocular injury from a stud gun has not hitherto been described.

\section{Case report}

A 17-year-old Chinese male industrial worker, who installs air-conditioners, was fixing a copper-stud into a stud gun (Fig. 1) with a screwdriver held in his right hand when the cartridge exploded accidentally. The stud hit him directly on the right eye from a distance of about $35 \mathrm{~cm}$.

\section{Examination}

$X$-ray films did not show a radio-opaque foreign body but clinical examination showed a spent stud (Fig. 2) impacted on the surface of the right eye-ball near the medial canthus. The visual acuity of the injured eye was reduced to appreciation of hand-movements; haemorrhage into the aqueous and vitreous prevented a view of the fundus.

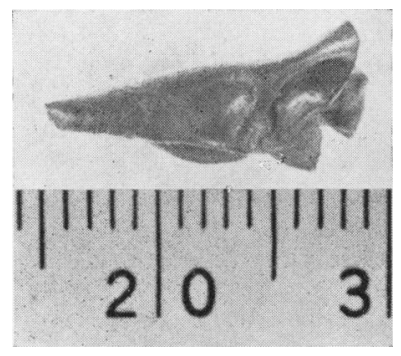

FIG. I Spent stud recovered from surface of eye-ball (cm.)

FIG. 2 Stud gun unmounted for fixation of stud and cartridge

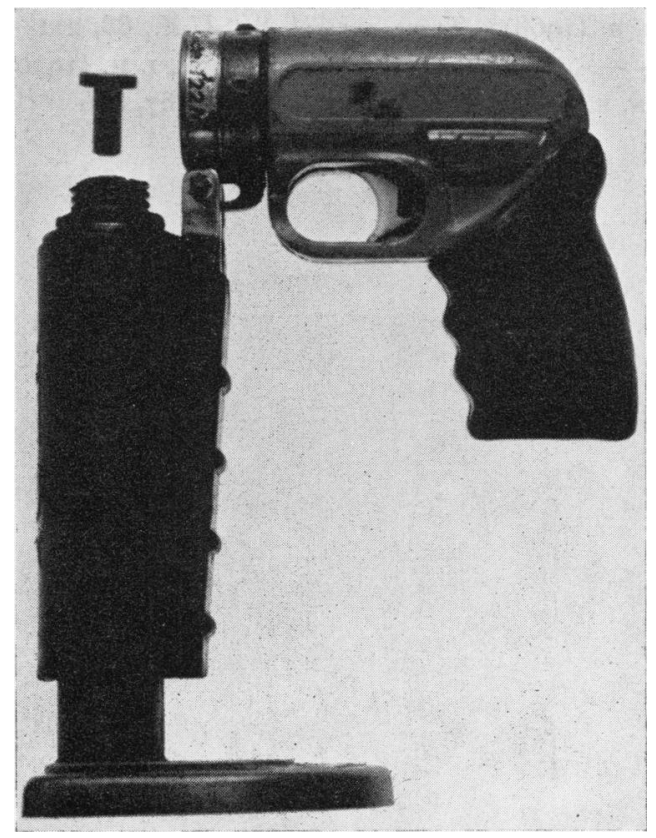




\section{Operation}

Under local anaesthesia, the impacted foreign body was readily dislodged with a pair of forceps, and it was found that the sclera beneath was perforated. A herniating blob of vitreous was abscised and the wound repaired with $5 / 0$ black silk sutures.

\section{Course}

3 weeks after the injury, the vitreous haemorrhage had cleared sufficiently to reveal a nearly total detachment of the retina with large irregular breaks corresponding to the site of contusion and an arrow-head tear opposite (Fig. 3).

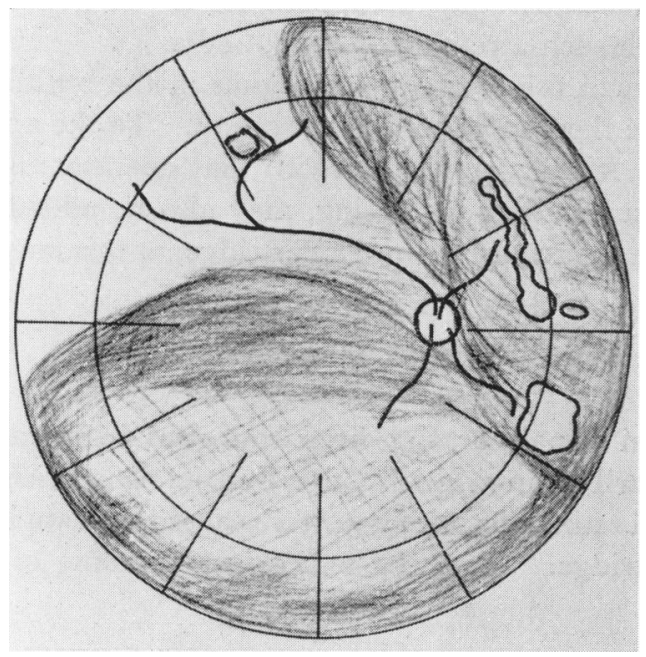

FIG. 3 Right fundus drawing showing traumatic vitreous haemorrhage and retinal detachment

\section{Second operation}

Retinal surgery was then performed under general anaesthesia. Surface diathermy was applied to the arrow-head tear at the Io o'clock meridian and diathermy combined with cryopexy was applied to the retinal breaks situated along the 2 to 4 o'clock meridians 14 to $16 \mathrm{~mm}$. behind the limbus. Subretinal fluid was drained from the lower temporal quadrant where there was a ballooned detachment and the globe was encircled with a silicone band with 6/o Dacron stay-sutures.

\section{Progress}

The cerclage was visible one week after the operation and by the third postoperative week the upper half of the retina was seen. Residual vitreous haemorrhage and blood clots finally cleared about 4 months after the injury, when the retina became clearly visible and was seen to be flat.

Result

The visual acuity improved from hand-movements to $6 / 12$, with a $-\mathrm{I} \cdot 25 \mathrm{D}$ lens.

\section{Discussion}

The patient showed two types of retinal detachment as a result of trauma. One was a perforation of the retina from contusion to the globe characterized by large, irregular retinal breaks corresponding to the site of contusion, and the other was a tear in the opposite side of the retina possibly following gliosis and vitreous traction. Mechanisms explaining both types of detachment have been described (Weidenthal and Schepens, r966; Ruiz, I969). 
Although Percival (1972) considered that surface diathermy or cryopexy did not alte

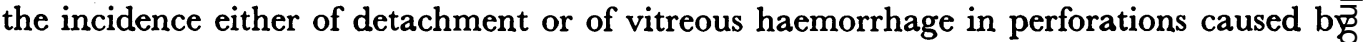
intraocular foreign bodies, Ruiz (1969) has advocated that treatment should be given to: the retina surrounding a perforation at the time of injury. In this case, vitreous haemor rhage had occurred at the time of injury and the foreign body was found impacted on the sclera which was perforated. Surface diathermy or cryopexy could have been but was no applied prophylactically, and the onset of detachment which ensued could not be ascer tained because of vitreous haemorrhage.

If the stud had been fired through the muzzle it could have caused a severe intraocular perforation, so that it is well to remember that a copper-stud is radio-lucent and non magnetic when one has to deal with such a retained foreign body.

With the increasing and widespread use of nail or stud guns in the building industry옹. workers should know how to handle these tools in absolute safety. To the advice emphaio sized in a leading article in British Medical Journal (1968) that operators of fixing tools. should receive adequate training in handling and firing, may also be added the caution that studs should not be forced with a screwdriver into a cartridge, as this may result in aroo accidental discharge.

\section{Summary}

Accidental injuries have been caused by nails or studs fired from guns designed to penetrate masonry or wood. A case is described in which ocular injuries, comprising contusion wounds, vitreous haemorrhage, and retinal detachment, were caused by a stud accidenta\$l discharged from an exploding cartridge. The need for careful handling of such tool re-emphasized.

\section{References}

LEAding ARTicle (1968) Brit. med. F., I, 462

LIM, к. H. (1964) Unpublished data

Percival, s. P. B. (1972) Brit. 7. Ophthal., 56, 462

RUIZ, R. S. (I969) Ibid., 53, 59

Weidenthal, D. T., and schepens, c. L. (1966) Amer. J. Ophthal., 62, 465 